\title{
PIBID: A INTERVENÇÃO PEDAGÓGICA NO RESTABELECIMENTO DO VÍNCULO PROFESSOR E ALUNO NO PROCESSO ENSINO - APRENDIZAGEM
}

\author{
Thaís de Castro Barbosa ${ }^{1}$ \\ Vera Lúcia Catoto Dias ${ }^{2}$ \\ Anamaria da Silva Martin Gascón Oliveira ${ }^{3}$
}

Resumo: Este trabalho é desenvolvido a partir da vivência pedagógica como bolsista do Programa Institucional de Bolsa de Iniciação à Docência, PIBID, convênio firmado entre a Instituição de Ensino Superior e a escola pública estadual. O trabalho tem como objetivo investigar a contribuição de proposta de intervenção pedagógica para o restabelecimento do vínculo professor e aluno no processo ensino e aprendizagem. A metodologia partiu de pesquisa bibliográfica seguida de pesquisa de campo, de abordagem qualitativa em educação do tipo estudo de caso etnográfico, pela observação participante durante o período de 2015-2016, realizada em uma escola pública, localizada no município de São José dos Campos. Os dados da pesquisa foram coletados a partir da aplicação de oficinas de intervenção pedagógica direcionadas a alunos do 3ำ ano do Ensino Fundamental l, identificados com dificuldades de socialização e de aprendizagem. Os resultados indicaram que a inserção de metodologia diferenciada de ensino contribuiu para a interação professor e aluno, pelo restabelecimento da confiança e do respeito mútuo anteriormente rompido no âmbito escolar.

Palavras-chave: Relação; Professor; Aluno; Aprendizagem; Vínculo.

\footnotetext{
1 Pedagogia/Universidade do Vale do Paraíba - UNIVAP, Faculdade de Educação e Arte, Brasil. E-mail: thaiscastro.pp@gmail.com.

2 Pedagogia/Universidade do Vale do Paraíba - UNIVAP, Faculdade de Educação e Arte, Brasil. E-mail: vcatoto@univap.br.

3 Pedagogia/Universidade do Vale do Paraíba - UNIVAP, Faculdade de Educação e Arte, Brasil. E-mail: gascon@univap.br.
} 